\title{
Systematic head and neck physical examination as a predictor of obstructive sleep apnea in class III obese patients
}

\author{
F.L. Martinho',2, R.P. Tangerina ${ }^{1}$, S.M.G.T. Moura², L.C. Gregório1 ${ }^{1}$, S. Tufik ${ }^{2}$ and \\ L.R.A. Bittencourt ${ }^{2}$
}

1'Departamento de Otorrinolaringologia e Cirurgia de Cabeça e Pescoço, Escola Paulista de Medicina, Universidade Federal de São Paulo, São Paulo, SP, Brasil

${ }^{2}$ Departamento de Psicobiologia, Instituto do Sono, Escola Paulista de Medicina, Universidade Federal de São Paulo, São Paulo, SP, Brasil

Correspondence to: F.L. Martinho, Rua Purpurina, 131, Conjunto 44, 05435-030 São Paulo, SP, Brasil

Fax: +55-11-3815-2116. E-mail: femartinho@uol.com.br

Our aim was to determine if anatomical abnormalities of the upper airway (UA) and facial skeleton of class III severely obese patients are related to the presence and severity of obstructive sleep apnea syndrome (OSAS). Forty-five patients (69\% females, mean age $46.5 \pm 10.8$ years) with a body mass index (BMI) over $40 \mathrm{~kg} / \mathrm{m}^{2}$ underwent UA and facial skeletal examinations as well as polysomnography. Mean BMI was $49 \pm 7 \mathrm{~kg} / \mathrm{m}^{2}$ and mean neck circumference was $43.4 \pm 5.1 \mathrm{~cm}$. Polysomnographic findings showed that $22 \%$ had a normal apnea-hypopnea index (AHI) and $78 \%$ had an AHI over 5 . The presence of OSAS was associated with younger age $(P=0.02)$, larger neck circumference $(P=0.004)$, presence of a voluminous lateral wall $(P=0.0002)$, posteriorized soft palate $(P=0.0053)$, thick soft palate $(P=0.0014)$, long uvula $(P=0.04)$, thick uvula $(P=0.0052)$, and inferior turbinate hypertrophy $(P=0.04)$. A larger neck circumference $(P=0.02)$, presence of a voluminous lateral wall $(P=0.04)$, posteriorized soft palate $(P=0.03)$, and thick soft palate $(P=0.04)$ were all associated with OSAS severity. The prevalence of OSAS in this group was high. A larger neck circumference and soft tissue abnormalities of the UA were markers for both the presence and severity of OSAS. Conversely, no abnormalities in the facial skeleton were associated with OSAS in patients with morbid obesity.

Key words: Obesity; Obstructive sleep apnea syndrome; Snore; Physical examination; Predictors

Research supported by Associação Fundo de Incentivo à Psicofarmacologia, FAPESP/CEPID. S. Tufik and L.R.A. Bittencourt are principal investigators of FAPESP and researchers of CNPq.

Received July 2, 2007. Accepted December 3, 2008

\section{Introduction}

Obstructive sleep apnea syndrome (OSAS), defined by the presence of excessive daytime somnolence and a polysomnogram apnea-hypopnea index (AHI) above 5 during sleep hours (1), affects $2 \%$ of women and $4 \%$ of men. This syndrome is prevalent among men aged 40 to 50 years as well as among obese people (2).

Obstructive sleep apnea syndrome has a multi-factorial physiopathology that partly derives from functional and structural alterations of the pharynx, including factors such as obesity and anatomical alterations of the upper airways (UA) and the facial skeleton (3). Obesity has been found to be a primary contributing factor to the occurrence and severity of OSAS (4), although some studies have shown that the correlation with OSAS severity is not observed consistently $(4,5)$. Studies have shown that the incidence of OSAS in obese people may vary from 39 to $95 \%$, leading to the question of what factors make one obese patient develop the syndrome and not another. Unfortunately, there is a lack of studies devoted to this question (6-9).

Patients who undergo bariatric surgery in order to treat 
morbid obesity have shown a reduction in the AHI after losing weight $(10,11)$. In some cases, however, there is no cure for the condition, suggesting that obesity may not be the only factor responsible for its physiopathology $(12,13)$.

Pillar et al. (14) observed that bariatric surgery was effective in maintaining weight reduction in 14 patients on a long-term basis (average follow-up: $71 \frac{1}{2}$ years), although $\mathrm{AHI}$ increased after this period of time. These findings indicate that the efficacy of obesity treatment is limited in terms of OSAS treatment, and that the syndrome tends to evolve over a period of years. In a systematic review of the literature, however, Buchwald et al. (15) found a success rate of $85.7 \%$ for curing OSAS by bariatric surgery.

The main anatomical alterations of the UA that correlate with the presence of the syndrome are a voluminous tongue, thick soft palate, web soft palate (i.e., the membrane formed through the low insertion of the posterior pillar in the uvula), posteriorized soft palate in relation to the oropharynx, voluminous lateral wall, long and thick uvula, hypertrophic tonsils, and a modified Mallampati index in classes III and IV (16-19). Anatomical alterations of the facial skeleton have also been correlated with OSAS, especially a retro-positioned mandible $(18,20,21)$.

Several studies have evaluated symptoms that could predict the occurrence and severity of the OSAS (16-19). In a study on 223 patients with OSAS, Zonato et al. (16) observed a modified Mallampati index in class III or IV subjects. They also found that three or more pharynx alterations were factors related to the severity of OSAS. In another study comparing patients with and without OSAS, Zonato et al. (22) showed that alterations in the UA and facial skeleton were the most prevalent in patients with OSAS, with the exception of a voluminous tongue marked by teeth, a web palate, and a deviated septum of degrees I and II. Although there are several studies of patients with OSAS, to our knowledge, no study to date has evaluated the UA and facial skeleton in a specific group of class III obese patients.

In view of the fact that obesity is strongly related to the presence of OSAS and that not all OSAS patients who have undergone bariatric surgery have been completely cured, we undertook the present study to evaluate the UA and facial skeleton of class III obese patients and to relate the findings to the presence and severity of OSAS.

\section{Material and Methods}

The study was performed at the outpatient clinic for breathing-related sleep disorders of the Otorhinolaryngology Department and at the Sleep Institute of the Federal University of São Paulo (UNIFESP) between March 2004 and March 2006. During this period, 97 patients with class III obesity from the Bariatric Surgery clinic of the Gastrosurgery Department of UNIFESP were evaluated regardless of sleep respiratory complaints. Of these, 45 patients consented to participate in the protocol (69\% females).

The study was approved by the Ethics Committee of the institution, and all patients gave written informed consent to participate. All patients were submitted to an evaluation protocol consisting of guided anamnesis, anthropometric physical examination (body mass index (BMI) and cervical circumference), a UA and facial skeletal examination, and polysomnography.

During anamnesis, patients were asked about the presence of symptoms related to OSAS, such as snoring, witnessed apnea, and daytime somnolence. The Epworth Sleepiness Scale was used to assess hypersomnolence.

BMI was calculated as $\mathrm{kg} / \mathrm{m}^{2}$ and patients with a BMI of $40 \mathrm{~kg} / \mathrm{m}^{2}$ or higher were assigned to obesity class III.

The UA and facial skeleton evaluation was performed by facial inspection, anterior rhinoscopy, oroscopy, dental occlusion evaluation, and flexible nasofibrolaryngoscopy. The facial skeleton evaluation consisted of observing signs of mandibular retrognathism as described by Ridley (23), the presence of dental occlusion class II, and the presence of an ogival palate (narrow hard palate).

We also evaluated the volume of the tongue through the marking of its lateral edge by the teeth, the soft palate, the uvula, the size of the palatine tonsils, and the modified Mallampati index. The soft palate was classified according to whether it was posteriorized in relation to the oropharynx, webbed, had a voluminous lateral wall (i.e., medialized tonsillar pillars), and/or was thick.

The modified Mallampati index was determined as described by Friedman et al. (17). Briefly, the patient was seated with his or her mouth wide open and tongue relaxed and resting inside the oral cavity. Patients were classified according to four degrees of severity. As proposed by Friedman et al. (17) and Zonato et al. (16), the size of the palatine tonsils was also classified into four categories.

Using anterior rhinoscopy and flexible nasofibrolaryngoscopy, we also evaluated the presence of deviations of the nasal septum and hypertrophy of the inferior nasal turbinates.

All patients underwent an overnight polysomnography (Somnologica, version 3.3.1, Iceland) coupled with monitoring by electroencephalogram, electrooculogram, chin and tibial electromyogram, and electrocardiogram. Airflow was monitored through a nasal cannula and oral thermistor, respiratory movements through a thoracoabdominal belt, oxyhemoglobin saturation through a wrist oximeter, snoring by a microphone, and sleep position by a sensor. 
Sleep stages were scored according to the criteria proposed by Rechtschtaffen and Kales (24). Arousals from sleep were determined according to the criteria of the American Sleep Disorders Association (25) and breathing events were scored according to the criteria proposed by the American Academy of Sleep Medicine (26).

OSAS was diagnosed according to the criteria of the International Sleep Disorders Classification (ISDC, 2005) (27), i.e., presence of sleepiness, an $\mathrm{AHI}$ above 5, snoring and/or witnessed apneas, or having an $\mathrm{AHI}$ above 15 without clinical complaints.

According to the above criteria, patients were divided into two groups, i.e., OSAS patients and non-OSAS patients. Findings were compared between groups using the Student $t$-test and the chi-square test. Differences in the degrees of severity of the syndrome were compared between groups using ANOVA and the chi-square test. All statistical analyses were carried out using the Statisoft 6.0 software, with the level of significance set at $P<0.05$.

\section{Results}

The average age of the patients was $46.5 \pm 10.8$ years, the average BMI was $49 \pm 7 \mathrm{~kg} / \mathrm{m}^{2}$, and the average cervical circumference was $43.4 \pm 5.1 \mathrm{~cm}$.

All patients reported snoring episodes, $93.3 \%$ referred to habitual snoring (snoring every night or almost every night), and $6.6 \%$ mentioned occasional snoring (rarely or sporadically). We observed that $77.8 \%$ of the patients had OSAS, $34.3 \%$ of them with light apnea (AHI between 5 and 15), $25.7 \%$ with moderate apnea (AHI between 15 and 30 ), and $40 \%$ with severe apnea (AHI above 30 ). Only $22 \%$ had an $\mathrm{AHI}$ within normal limits and reported no clinical complaints, indicating that this group of obese patients did not have OSAS. We found that the largest cervical circumferences and the youngest ages were more prevalent in the group with OSAS (Table 1). Gender and BMI did not differ

Table 1. Clinical aspects of class III obese non-OSAS and OSAS patients.

\begin{tabular}{lccl}
\hline & $\begin{array}{c}\text { Non-OSAS } \\
\text { patients }(\mathrm{N}=10)\end{array}$ & $\begin{array}{c}\text { OSAS } \\
\text { patients }(\mathrm{N}=35)\end{array}$ & $\begin{array}{c}\mathrm{P} \\
\text { value }\end{array}$ \\
\hline Male:Female & $0: 100 \%$ & $40: 60 \%$ & $\mathrm{NS}^{*}$ \\
Age (years) & $53.1 \pm 9.1$ & $44.6 \pm 10.6$ & $0.02^{* *}$ \\
BMl $\left(\mathrm{kg} / \mathrm{m}^{2}\right)$ & $47.8 \pm 6$ & $49.8 \pm 6.9$ & $\mathrm{NS}^{*}$ \\
$\begin{array}{l}\text { Neck circumference } \\
(\mathrm{cm})\end{array}$ & $39.5 \pm 2.0$ & $44.6 \pm 5.2$ & $0.004^{* *}$ \\
\hline
\end{tabular}

Data are reported as mean \pm SD. OSAS $=$ obstructive sleep apnea syndrome; BMI = body mass index. ${ }^{*}$ Based on the chisquare test; ${ }^{*}$ based on the Student $t$-test. NS = nonsignificant. between groups.

The polysomnographic findings for the two groups are described in Table 2. As expected, there was a significant difference between groups in $\mathrm{AHI}$ and in minimum oxyhemoglobin saturation.

We also found that pharyngeal alterations were more prevalent in the OSAS group, although alterations of the facial skeleton did not differ significantly from those of the non-OSAS group (Table 3). Finally, the largest cervical

Table 2. Polysomnography data of class III obese non-OSAS and OSAS patients.

\begin{tabular}{lcc}
\hline & $\begin{array}{c}\text { Non-OSAS patients } \\
(\mathrm{N}=10)\end{array}$ & $\begin{array}{c}\text { OSAS patients } \\
(\mathrm{N}=35)\end{array}$ \\
\hline $\mathrm{AHI}$ & $2.9 \pm 1.5$ & $38.7 \pm 31.6^{*}$ \\
$\mathrm{SaO}_{2}$ min (\%) & $83 \pm 5.9 \%$ & $73 \pm 9.1 \%^{*}$ \\
Sleep efficiency (\%) & $72 \pm 10.7 \%$ & $74 \pm 15.2 \%$ \\
Stage 1 (\%) & $6 \pm 3.6 \%$ & $8 \pm 7.9 \%$ \\
Stage 2 (\%) & $59 \pm 11.9 \%$ & $65 \pm 9.8 \%$ \\
Stages 3 and 4 (\%) & $15 \pm 8.2 \%$ & $10 \pm 8.9 \%$ \\
REM (\%) & $19 \pm 8.0 \%$ & $16 \pm 8.6 \%$ \\
\hline
\end{tabular}

Data are reported as mean $\pm S D$. OSAS = obstructive sleep apnea syndrome; $\mathrm{AHI}=$ apnea and hypopnea per sleep hour index; $\mathrm{SaO}_{2} \mathrm{~min}=$ minimum oxyhemoglobin saturation; $\mathrm{REM}=$ rapid eye movement. ${ }^{*} \mathrm{P}<0.001$, OSAS compared to non-OSAS patients (Student $t$-test).

Table 3. Comparison of the physical examination variables between class III obese non-OSAS and OSAS patients.

\begin{tabular}{lcc}
\hline & $\begin{array}{c}\text { Non-OSAS patients } \\
(\mathrm{N}=10)\end{array}$ & $\begin{array}{c}\text { OSAS patients } \\
(\mathrm{N}=35)\end{array}$ \\
\hline Ogival-palate & $10 \%$ & $8.6 \%$ \\
Retro-positioned mandible & $0 \%$ & $0 \%$ \\
Class II occlusion & $0 \%$ & $2.9 \%$ \\
Tongue edge crenation & $30 \%$ & $51.4 \%$ \\
Web-palate & $90 \%$ & $77.1 \%$ \\
Posterior palate & $0 \%$ & $45.7 \% *$ \\
Thick palate & $10 \%$ & $68.6 \%{ }^{*}$ \\
Long uvula & $10 \%$ & $45.7 \% *$ \\
Thick uvula & $20 \%$ & $71.4 \%{ }^{*}$ \\
Voluminous lateral wall & $10 \%$ & $65.7 \% *$ \\
MMC classes I and II & $30 \%$ & $25.8 \%$ \\
MMC classes III and IV & $70 \%$ & $74.2 \%$ \\
Previous tonsillectomy & $20 \%$ & $14.3 \%$ \\
Degree I and II tonsils & $70 \%$ & $74.2 \%$ \\
Degree III and IV tonsils & $10 \%$ & $11.5 \%$ \\
Degree I septal deviation & $10 \%$ & $11.4 \%$ \\
Degree II septal deviation & $0 \%$ & $8.6 \%$ \\
Degree III septal deviation & $0 \%$ & $2.9 \%$ \\
Turbinate hypertrophy & $30 \%$ & $65.7 \% *$ \\
\hline
\end{tabular}

OSAS = obstructive sleep apnea syndrome; MMC = modified Mallampati classification. ${ }^{*} P<0.05$, OSAS compared to nonOSAS patients (chi-square test). 
circumference and the pharyngeal alterations were more prevalent in patients with severe OSAS $(\mathrm{AHI}>30)$ than in patients without it (Figures 1-4).

\section{Discussion}

There is a high prevalence of habitual snoring coupled with OSAS in patients with class III obesity (4-9). In the present study, however, $22 \%$ of the patients did not show signs of OSAS. Although it is known that the prevalence of OSAS in the general population is higher among males (1), we did not find any difference between genders in our group of patients. Furthermore, most studies have been conducted on age-matched OSAS patients (2), whereas in our study OSAS patients were younger than non-OSAS patients.

Although obesity is a factor very much related to the presence of OSAS (4-9), some studies have failed to show a correlation between BMI and the severity of OSAS $(4,5)$. Our findings are consistent with this observation. This result might have been due to the fact that our sample was restricted to the most severely obese subjects, whereas the studies that evaluated $\mathrm{AHI}$ and $\mathrm{BMI}$ were conducted on patients with normal BMI or on patients with varying levels of obesity (4-9).

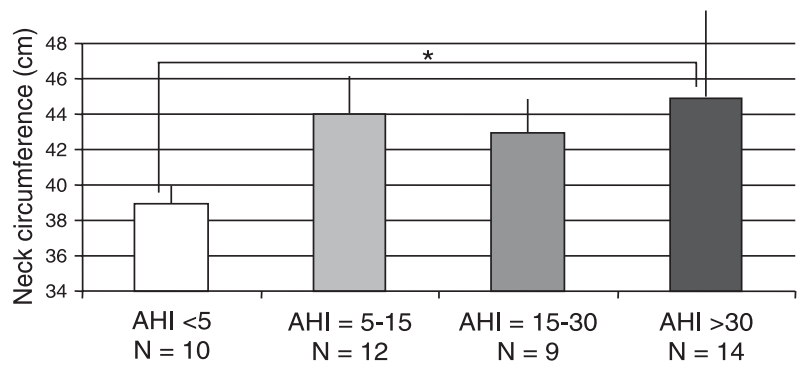

Figure 1. Neck circumference and severity of obstructive sleep apnea syndrome in class III obese patients. Data are reported as means $\pm \mathrm{SD}$ for $\mathrm{N}$ subjects in each group. $\mathrm{AHI}=$ apnea-hypopnea index. ${ }^{*} \mathrm{P}=0.02$ (ANOVA).

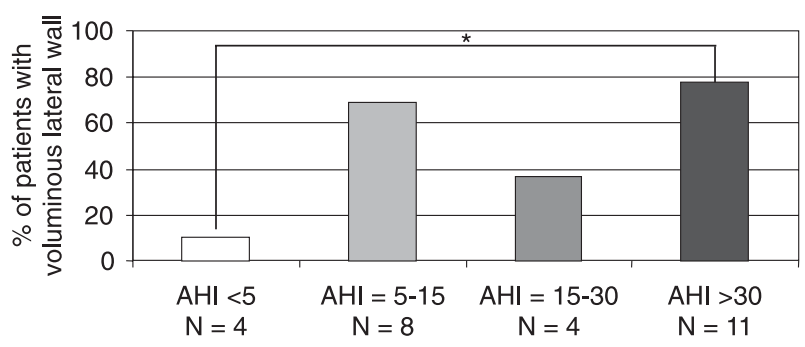

Figure 2. Upper airway anatomic abnormality (voluminous lateral wall) and severity of obstructive sleep apnea syndrome in class III obese patients. $\mathrm{AHI}=$ apnea-hypopnea index. ${ }^{*} \mathrm{P}=0.04$ (chi-square test).
Cervical circumference, which is considered to be one of the best markers of the presence and severity of OSAS (4), was also a good predictor of both the presence and severity of OSAS in our select group of patients with class III obesity.

In contrast to that previously reported $(18,20-22)$, our findings regarding the prevalence of facial skeletal alterations in OSAS patients with class III obesity did not show a significant difference in the presence or the severity of OSAS between the two groups of patients.

The UA alterations related to the presence of OSAS are most likely related to the edema resulting from respiratory trauma and snoring. Because our sample consisted of patients with a marked degree of obesity, we also found an elevated average $\mathrm{AHI}$ value. These conditions may have favored our observation of a higher prevalence of UA soft tissue alterations.

The presence of hypertrophy of the palatine tonsils and of modified Mallampati values were not correlated with the presence or the severity of the syndrome. The modified Mallampati value has increasingly been considered a good predictor of the occurrence as well as the severity of OSAS $(16,17,22)$. In our patients, however, we did not find such a correlation.

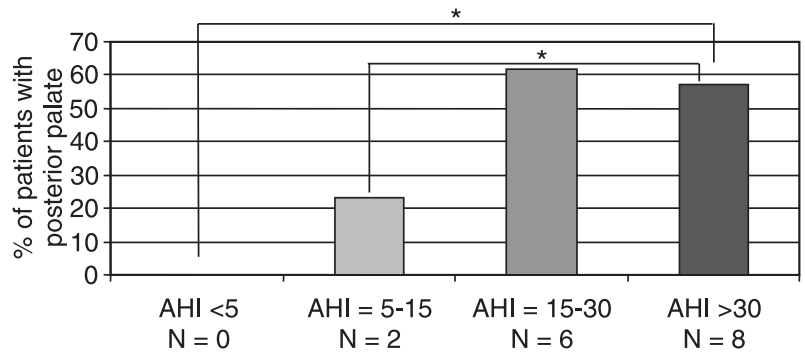

Figure 3. Upper airway anatomic abnormality (posterior palate) and severity of obstructive sleep apnea syndrome in class III obese patients. $\mathrm{AHI}=$ apnea-hypopnea index. ${ }^{*} \mathrm{P}=0.03$ (chisquare test).

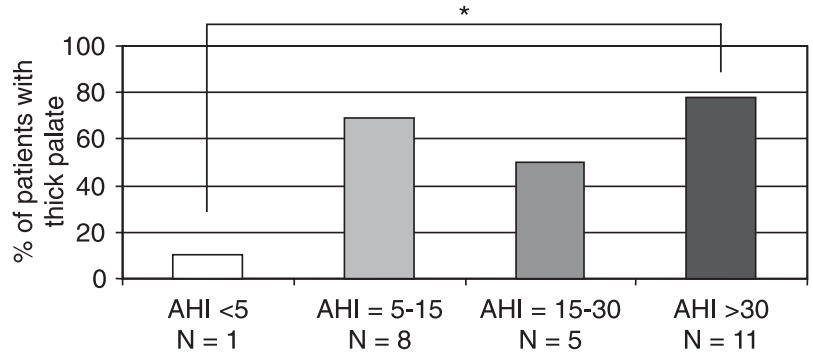

Figure 4. Upper airway anatomic abnormality (thick palate) and severity of obstructive sleep apnea syndrome in class III obese patients. $\mathrm{AHI}=$ apnea-hypopnea index. ${ }^{*} \mathrm{P}=0.04$ (chi-square test). 
The prevalence of OSAS in this group of class III obese patients was higher than in the general population, supporting the correlation between obesity and OSAS. We also confirmed that a larger neck circumference was a marker for both the presence and severity of OSAS. Ab- normalities of UA soft tissue were related to OSAS presence and severity; however, facial skeleton abnormalities were not related to the presence of OSAS or severity in patients with morbid obesity referred for bariatric surgery.

\section{References}

1. Young T, Palta M, Dempsey J, Skatrud J, Weber S, Badr S. The occurrence of sleep-disordered breathing among middle-aged adults. N Engl J Med 1993; 328: 1230-1235.

2. Olson LG, King MT, Hensley MJ, Saunders NA. A community study of snoring and sleep-disordered breathing. Prevalence. Am J Respir Crit Care Med 1995; 152: 711-716.

3. Kuna S, Remmers JE. Anatomy and physiology of upper airway obstruction. In: Krieger MH, Roth T, Dement WC (Editors), Principles and practice of sleep medicine. 3rd edn. Philadelphia: WB Saunders; 2000. p 840-858.

4. Ward Flemons W, McNicholas WT. Clinical prediction of the sleep apnea syndrome. Sleep Med Rev 1997; 1: 19-32.

5. Fogel RB, Malhotra A, Dalagiorgou G, Robinson MK, Jakab $\mathrm{M}$, Kikinis R, et al. Anatomic and physiologic predictors of apnea severity in morbidly obese subjects. Sleep 2003; 26 : 150-155.

6. Valencia-Flores M, Orea A, Castano VA, Resendiz M, Rosales M, Rebollar V, et al. Prevalence of sleep apnea and electrocardiographic disturbances in morbidly obese patients. Obes Res 2000; 8: 262-269.

7. Van Boxem TJ, de Groot GH. Prevalence and severity of sleep disordered breathing in a group of morbidly obese patients. Neth J Med 1999; 54: 202-206.

8. Broussolle C, Piperno D, Gormand F, Cambursano H, Berthier M, Perrin-Fayolle M, et al. Sleep apnea syndrome in obese patients: are there any predictive factors? Rev Med Interne 1994; 15: 161-165.

9. Vgontzas AN, Tan TL, Bixler EO, Martin LF, Shubert D, Kales A. Sleep apnea and sleep disruption in obese patients. Arch Intern Med 1994; 154: 1705-1711.

10. O'Brien PE, Dixon JB, Brown W, Schachter LM, Chapman $\mathrm{L}$, Burn AJ, et al. The laparoscopic adjustable gastric band (Lap-Band): a prospective study of medium-term effects on weight, health and quality of life. Obes Surg 2002; 12: 652660.

11. Scheuller M, Weider D. Bariatric surgery for treatment of sleep apnea syndrome in 15 morbidly obese patients: longterm results. Otolaryngol Head Neck Surg 2001; 125: 299302.

12. O'Keeffe T, Patterson EJ. Evidence supporting routine polysomnography before bariatric surgery. Obes Surg 2004; 14 : 23-26.

13. Guardiano SA, Scott JA, Ware JC, Schechner SA. The long-term results of gastric bypass on indexes of sleep apnea. Chest 2003; 124: 1615-1619.

14. Pillar G, Peled R, Lavie P. Recurrence of sleep apnea without concomitant weight increase 7.5 years after weight reduction surgery. Chest 1994; 106: 1702-1704.
15. Buchwald $H$, Avidor $Y$, Braunwald $E$, Jensen MD, Pories $W$, Fahrbach $\mathrm{K}$, et al. Bariatric surgery: a systematic review and meta-analysis. JAMA 2004; 292: 1724-1737.

16. Zonato Al, Bittencourt LR, Martinho FL, Junior JF, Gregorio LC, Tufik S. Association of systematic head and neck physical examination with severity of obstructive sleep apneahypopnea syndrome. Laryngoscope 2003; 113: 973-980.

17. Friedman M, Tanyeri H, La Rosa M, Landsberg R, Vaidyanathan K, Pieri S, et al. Clinical predictors of obstructive sleep apnea. Laryngoscope 1999; 109: 1901-1907.

18. Woodson BT. Examination of the upper airway. Oral Maxillofac Surg Clin North Am 1995; 7: 257-267.

19. Rombaux $P$, Bertrand $B$, Boudewyns A, Deron $P$, Goffart $Y$, Hassid $S$, et al. Standard ENT clinical evaluation of the sleep-disordered breathing patient; a consensus report. Acta Otorhinolaryngol Belg 2002; 56: 127-137.

20. Teculescu DB, Montaut-Verient B, Hannhart B, Virion JM, Cornette A, Michaely JP. Breathing pauses during sleep: can a non-invasive ENT examination help identify subjects at risk in epidemiological settings? Med Hypotheses 2001; 56: 653-656.

21. Tsai WH, Remmers JE, Brant R, Flemons WW, Davies J, Macarthur C. A decision rule for diagnostic testing in obstructive sleep apnea. Am J Respir Crit Care Med 2003; 167: 1427-1432.

22. Zonato Al, Martinho FL, Bittencourt LR, de Oliveira Campones BO, Gregorio LC, Tufik S. Head and neck physical examination: comparison between nonapneic and obstructive sleep apnea patients. Laryngoscope 2005; 115: 1030-1034.

23. Ridley MB. Aesthetic facial proportions. In: Papel ID, Nachlis NE (Editors), Facial plastic and reconstructive surgery. St. Louis: Mosby - Year Book; 1992. p 106.

24. Rechtschtaffen A, Kales A. A manual of standardized terminology, techniques and scoring system for sleep stages of human subjects. Los Angeles: UCLA Brain Information Service/Brain Research Institute, 1968.

25. EEG arousals: scoring rules and examples: a preliminary report from the Sleep Disorders Atlas Task Force of the American Sleep Disorders Association. Sleep 1992; 15: 173-184.

26. Sleep-related breathing disorders in adults: recommendations for syndrome definition and measurement techniques in clinical research. The Report of an American Academy of Sleep Medicine Task Force. Sleep 1999; 22: 667-689.

27. American Academy of Sleep Medicine. ICSD-2 - International classification of sleep disorders. Diagnostic and coding manual. Westchester, IL: American Academy of Sleep Medicine; 2005. 